US Army Corps

of Engineers ${ }_{\circledast}$

Engineer Research and

Development Center

\title{
Wave-Speed-Based Performance Indicators for Portugues Dam
}

Ziyad H. Duron, Peter Orme, Spenser Anderson,

October 2018

Henry Diaz-Alvarez, Vincent P. Chiarito,

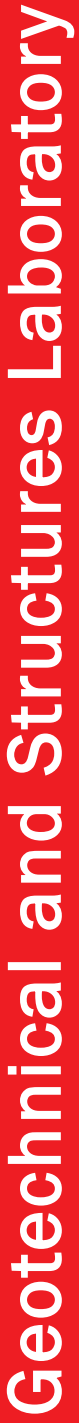

and Mihan H. McKenna

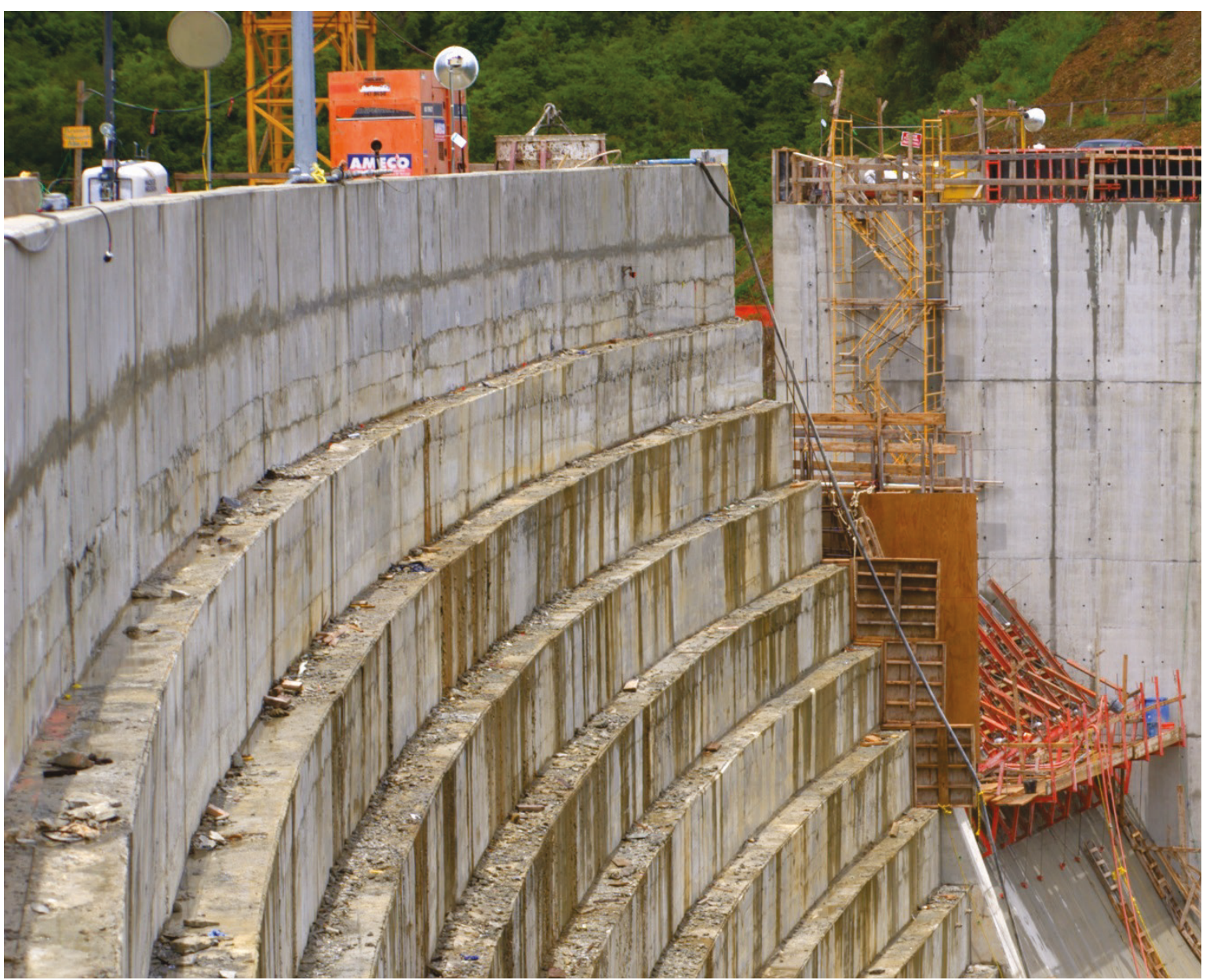


The U.S. Army Engineer Research and Development Center (ERDC) solves the nation's toughest engineering and environmental challenges. ERDC develops innovative solutions in civil and military engineering, geospatial sciences, water resources, and environmental sciences for the Army, the Department of Defense, civilian agencies, and our nation's public good. Find out more at www.erdc.usace.army.mil.

To search for other technical reports published by ERDC, visit the ERDC online library at http://acwc.sdp.sirsi.net/client/default. 


\title{
Wave-Speed-Based Performance Indicators for Portugues Dam
}

\author{
Henry Diaz-Alvarez, Vincent P. Chiarito, and Mihan H. McKenna \\ Geotechnical and Structural Laboratory \\ U.S. Army Engineer Research and Development Center \\ 3909 Halls Ferry Road \\ Vicksburg, MS 39180-6199 \\ Ziyad H. Duron, Peter Orme and Spenser Anderson \\ Harvey Mudd College \\ 260 E. Foothill Boulevard \\ Claremont, CA 91711
}

Final Report

Approved for public release; distribution is unlimited.

\author{
Prepared for U.S. Army Corps of Engineers \\ Washington, DC 20314-1000 \\ Under Work Unit 33143
}




\section{Abstract}

Roller Compacted Concrete (RCC) construction techniques are used to raise existing dams and to build new dams. A particular and assumed advantage of the RCC technique is improved homogeneity in concrete condition throughout the dam. An opportunity to evaluate this on a large RCC dam was made available by the U.S. Army Corps of Engineers at Portugues Dam. Through the application of a relatively new testing technique, estimates of a wave-speed-based Performance Indicator (PI) of the dam were obtained. The PI relates wave speeds associated with shear wave propagation in the dam to compression wave speeds for healthy concrete. Values ranging from 1.7-2.2 for Portugues Dam compare favorably to a value of 1.6 for nominal concrete.

DISCLAIMER: The contents of this report are not to be used for advertising, publication, or promotional purposes. Citation of trade names does not constitute an official endorsement or approval of the use of such commercial products. All product names and trademarks cited are the property of their respective owners. The findings of this report are not to be construed as an official Department of the Army position unless so designated by other authorized documents. 


\section{Contents}

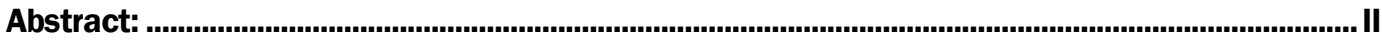

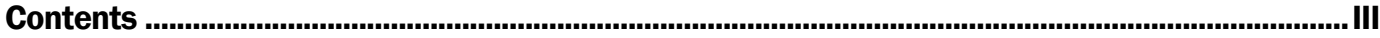

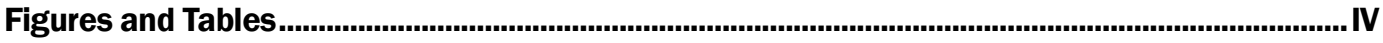

Preface ............................................................................................................................................. V

Unit Conversion Factors .................................................................................................................... VI

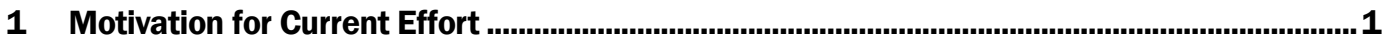

2 Performance-Based Testing of Portugues Dam - Responses and Fundamental Behavior .............................................................................................................................................................. 2

3 Wave-Speed-Based Performance Indicators.....................................................................10

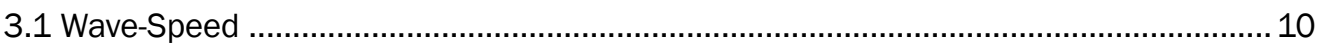

3.2 Performance Indicator meaning and interpretation ................................................. 13

4 Summary and Observations.............................................................................................15

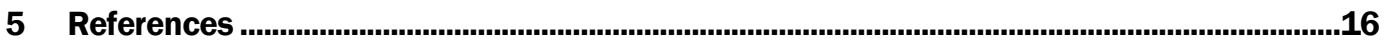




\section{Figures and Tables}

\section{Figures}

Figure 1. Portugues Dam; photograph taken August 2013 at the conclusion of PBT and prior to completion of the ogee spillway 2

Figure 2. Cold Gas Thrusters mounted onto Portugues Dam...............................................................

Figure 3. Typical force pulse delivered by the CGT to the dam. ........................................................

Figure 4. Induced acceleration response at CGT attachment location. ............................................. 4

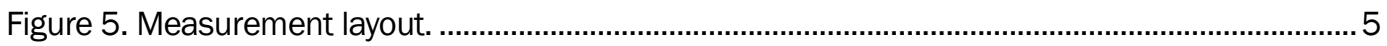

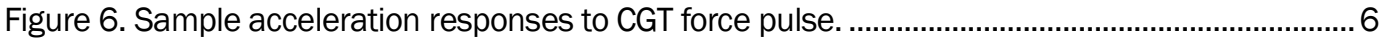

Figure 7. Sample shock response spectra associated with PBT responses at Monoliths 6 and 14

Figure 8. Response shape at $4.8 \mathrm{~Hz}$; modal amplitude is normalized to 1 as indicated. ................... 9

Figure 9. Wave propagation in Monolith No. 8 ............................................................................10

Figure 10. Measurement layouts for determining wave speed estimates along the crest (top) and in monolith no. 8 (bottom) at Portugues Dam; Locations $8 \mathrm{~b}$ and $8 \mathrm{c}$ correspond to the mid-height and the base of the monolith, respectively.

\section{Tables}

Table 1. Resonances identified from PBT at Portugues Dam.

Table 2. Wave speed estimates along the west portion of the crest (top Table) and within monolith no. 8 (bottom Table). The estimates within monolith no. 8 were obtained from a series of tests that captured responses at the midpoint and the base of the monolith.

Table 3. Wave speed comparison along crest and within monolith no. 8 . 


\section{Preface}

This study was conducted for the Office of the Assistant Secretary of the Army for Acquisition, Logistics, and Technology (ASAALT) under Project "Remote Assessment of Critical Infrastructure."

The work was performed by the Structural Engineering Branch (GSS) of the Geosciences and Structures Division (GS), U.S. Army Engineer Research and Development Center, Geotechnical and Structures Laboratory (ERDC-GSL). At the time of publication, Mr. Charles W. Ertle was Chief, CEERD-GSS; Mr. James Davis was Chief, CEERD-GS; and Ms. Pamela G. Kinnebrew, CEERD-GZT, was the Technical Director for Military Engineering. The Deputy Director of ERDC-GSL was Dr. William P. Grogan, and the Director was Mr. Bartley P. Durst.

COL Ivan P. Beckman was the Commander of ERDC, and Dr. David W. Pittman was the Director. 


\section{Unit Conversion Factors}

\begin{tabular}{|c|c|c|}
\hline Multiply & By & To Obtain \\
\hline atmosphere (standard) & 101.325 & kilopascals \\
\hline bars & 100 & kilopascals \\
\hline degrees Fahrenheit & $(F-32) / 1.8$ & degrees Celsius \\
\hline feet & 0.3048 & meters \\
\hline inches & 0.0254 & meters \\
\hline yards & 0.9144 & meters \\
\hline
\end{tabular}




\section{Motivation for Current Effort}

Performance Based Testing (PBT) of large civil structures has the potential to provide information relevant to the evaluation of a structure's response to hazardous loading conditions. Originally developed during the field investigation of large cable suspension bridges in Maine and in Ohio, the technique has been adapted to large concrete dams and has been demonstrated on both healthy and damaged structures. A distinguishing characteristic of PBT is the use of an excitation source that delivers a largeamplitude, broad-frequency band impulse that induces transient response behavior. The transient nature of the induced responses contains fundamental behavior that can be used for validating numerical models, evaluating structural condition, and predicting response levels in the structure under a wide range of loading conditions.

Portugues Dam is a thick-arch, roller compacted concrete (RCC) dam built in Puerto Rico by the U.S. Army Corps of Engineers and is one of only about 10 such dams in the world. The dam is $220 \mathrm{ft}$ tall and $1230 \mathrm{ft}$ long and has an ogee spillway $140 \mathrm{ft}$ long. Base and crest thicknesses are $111 \mathrm{ft}$ and $30 \mathrm{ft}$, respectively; and more than 355,000 cubic yards of concrete was used in its construction. The dam was designed as a three-dimensional structure with closed contraction joints and underwent an extensive RCC design and testing program. The tensile strength of the horizontal lift joints plays an important role in the dam's ability to perform under seismic loading, which leads to the focus of the current study.

Dams built by using RCC are assumed to exhibit improved homogeneity over dams built by using traditional block pours, and a measure of the degree of homogeneity present in a dam is wave speed.

This report provides an overview of the PBT performed on Portugues Dam and illustrates the transient behavior across the crest and along one of the monolith blocks. It includes samples of measured responses in the dam, along with results from a Shock Response Spectrum (SRS) analysis that was used to highlight resonances and response shapes in the dam. The report also describes a wave-speed-based Performance Indicator (PI) that can be used to evaluate existing and changing concrete conditions in the dam. 


\section{Performance-Based Testing of Portugues Dam - Responses and Fundamental Behavior}

Portugues Dam is located on the Portugues River three miles northwest of the city of Ponce in Puerto Rico. The dam was completed in early 2014 and provides flood control for a region of more than 40,000 inhabitants and over 13,000 residential structures. Figure 1 is a photograph of the dam at the time of testing during the summer of 2013.

Figure 1. Portugues Dam; photograph taken August 2013 at the conclusion of PBT and prior to completion of the ogee spillway.

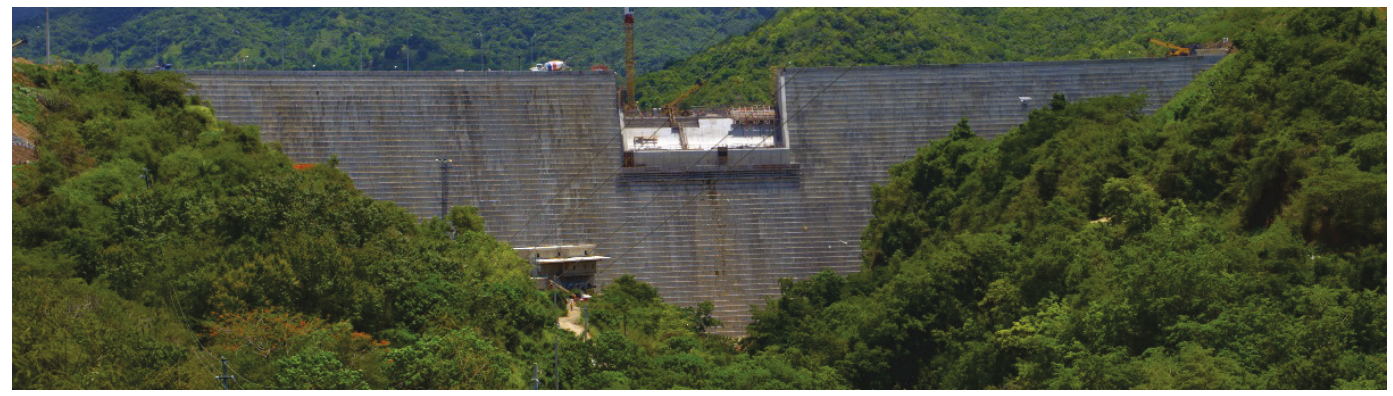

The development of the PBT technique is described in Duron et al. (2013) and its adaptation to a large, concrete multiple-arch dam is described in Goldkamp et al. (2014) and Edelman et al. (2014). Found in the references are specifics regarding instrumentation, particularly those associated with the excitation device that is referred to as a Cold Gas Thruster (CGT); motion sensors; and acquisition systems and parameters. Primary testing at Portugues Dam was conducted using one CGT, but a second CGT was used to investigate potential advantages of multiple (two) devices. A photograph of the CGTs mounted on the crest of the dam is shown in Figure 2.

A typical force pulse delivered to the dam from the CGT is shown in Figure 3 .

Peak force levels ranged between 6,000 and 8,000 lb, and repeatability in terms of the pulse width (10 msec) and dissipation was very good for the tests at Portugues Dam. Additional CGT instrumentation included a shock accelerometer that monitored the acceleration induced in the dam at the CGT attachment location; a typical response is shown in Figure 4. 
Figure 2. Cold Gas Thrusters mounted onto Portugues Dam.

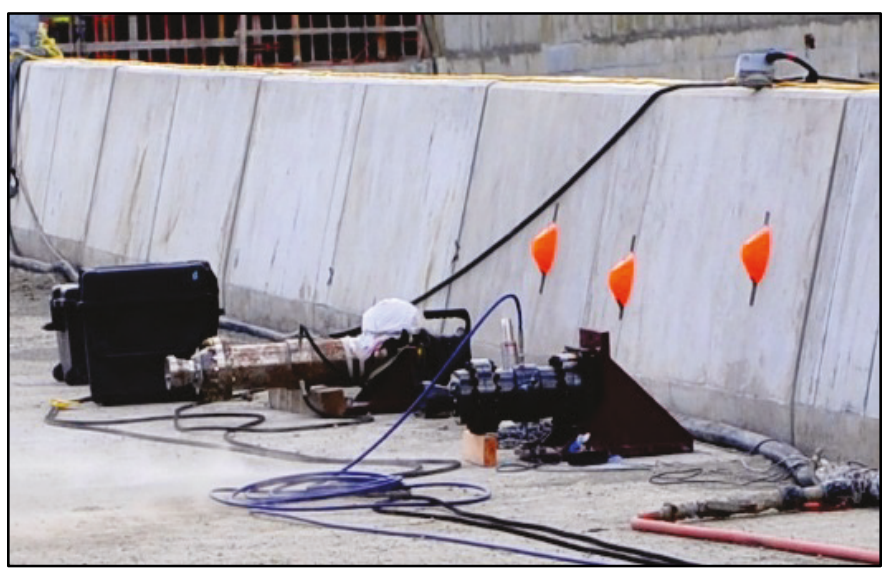

Figure 3. Typical force pulse delivered by the CGT to the dam.

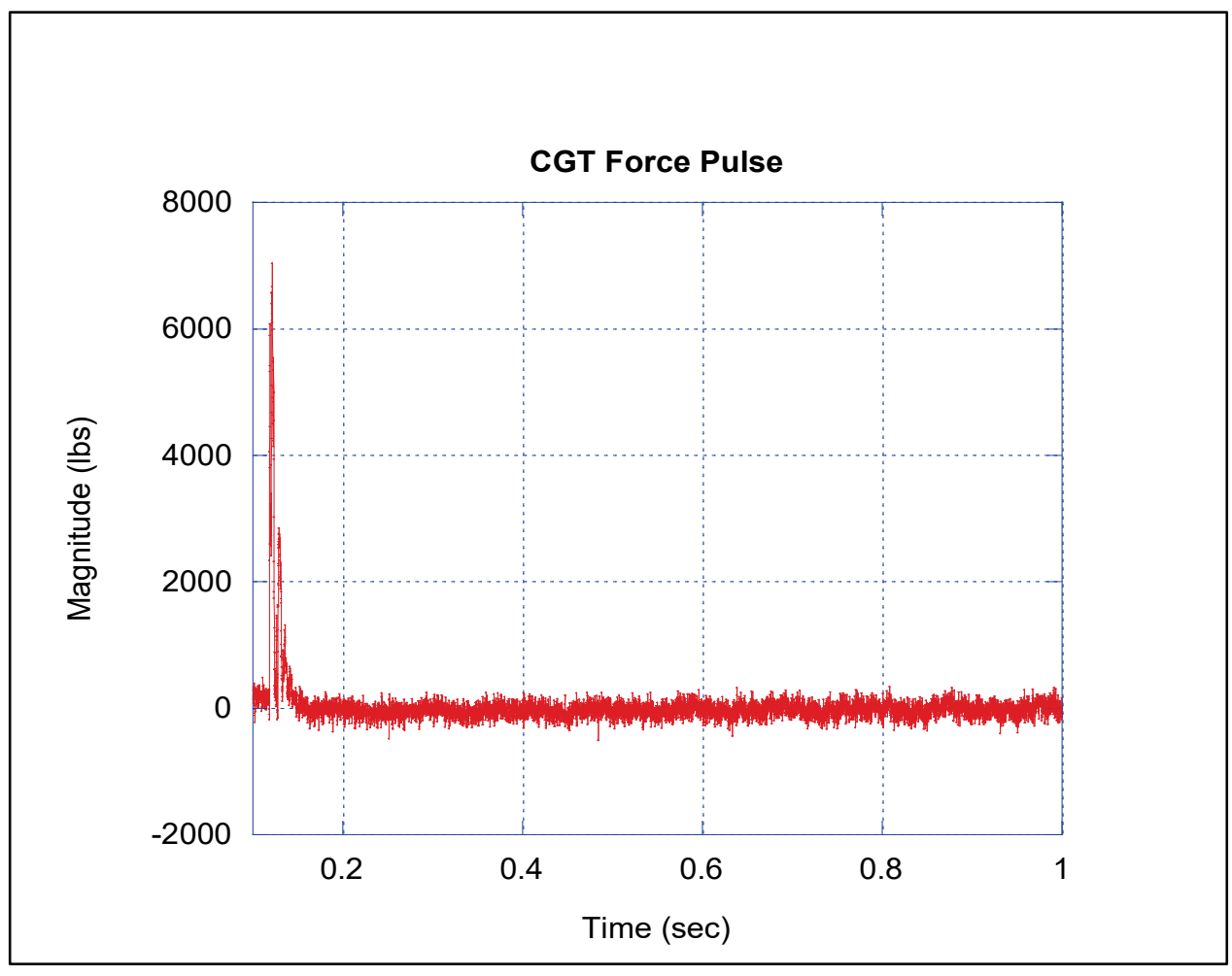


Figure 4. Induced acceleration response at CGT attachment location.

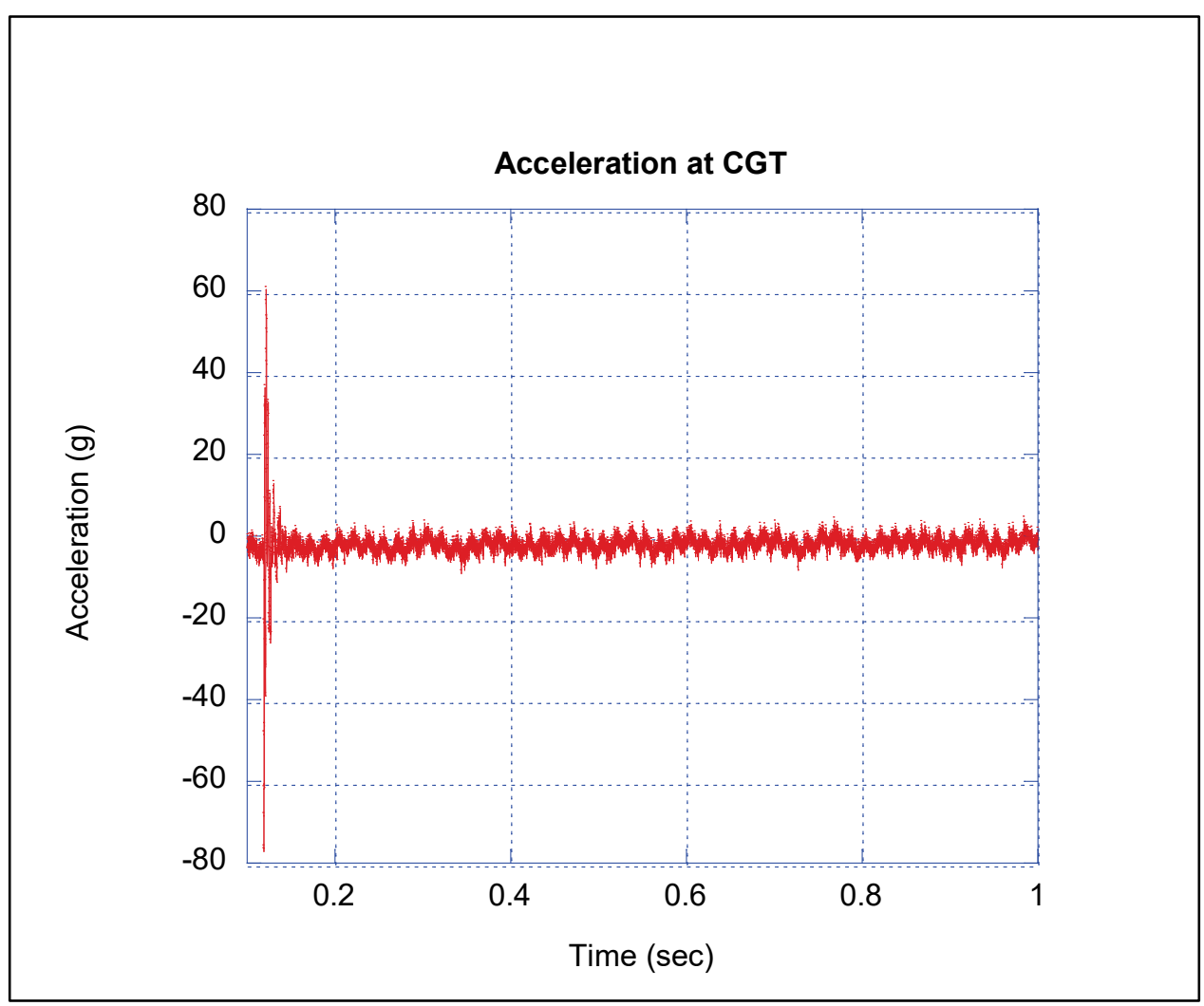

Peak acceleration levels approach 80 g's and are associated with the acceleration of the CGT at load delivery. These levels have been observed in previous PBTs of dams, and the ratio of the peak force and the peak acceleration levels in the measured responses correspond to the mass (or weight) of the CGT itself (approximately $150 \mathrm{lb}$ as configured at Portugues Dam). As a result and based on previous experience with the testing technique and instrumentation, the acceleration levels and overall character of the shock acceleration response are consistent with expected behavior and are indicative of satisfactory CGT performance.

Figure 5 shows the measurement layout used during PBT at the dam, which was designed to capture responses along the crest and along the height of one monolith. 
Figure 5. Measurement layout.

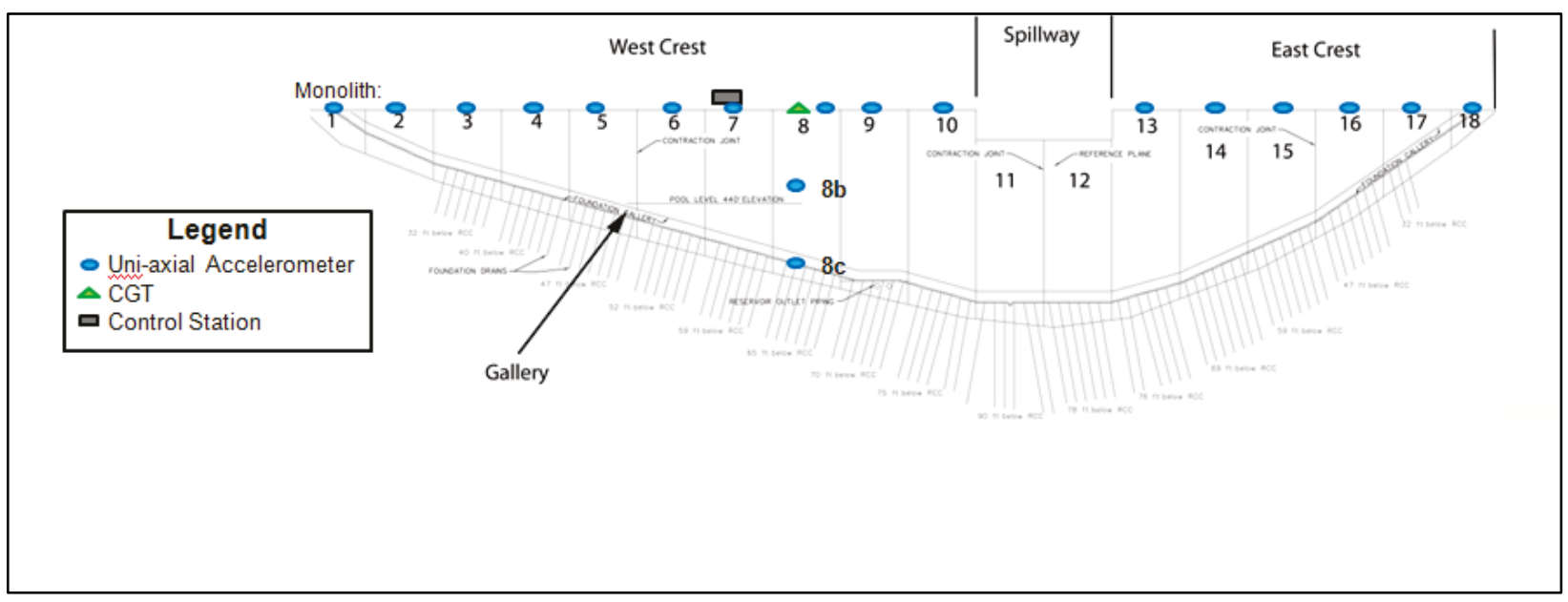

Accelerometers were oriented radially along the crest in the stream direction, and the CGT remained anchored to the crest at monolith No. 8 throughout the test. Sample responses on each side of the spillway are shown in Figure 6. 
Figure 6. Sample acceleration responses to CGT force pulse.

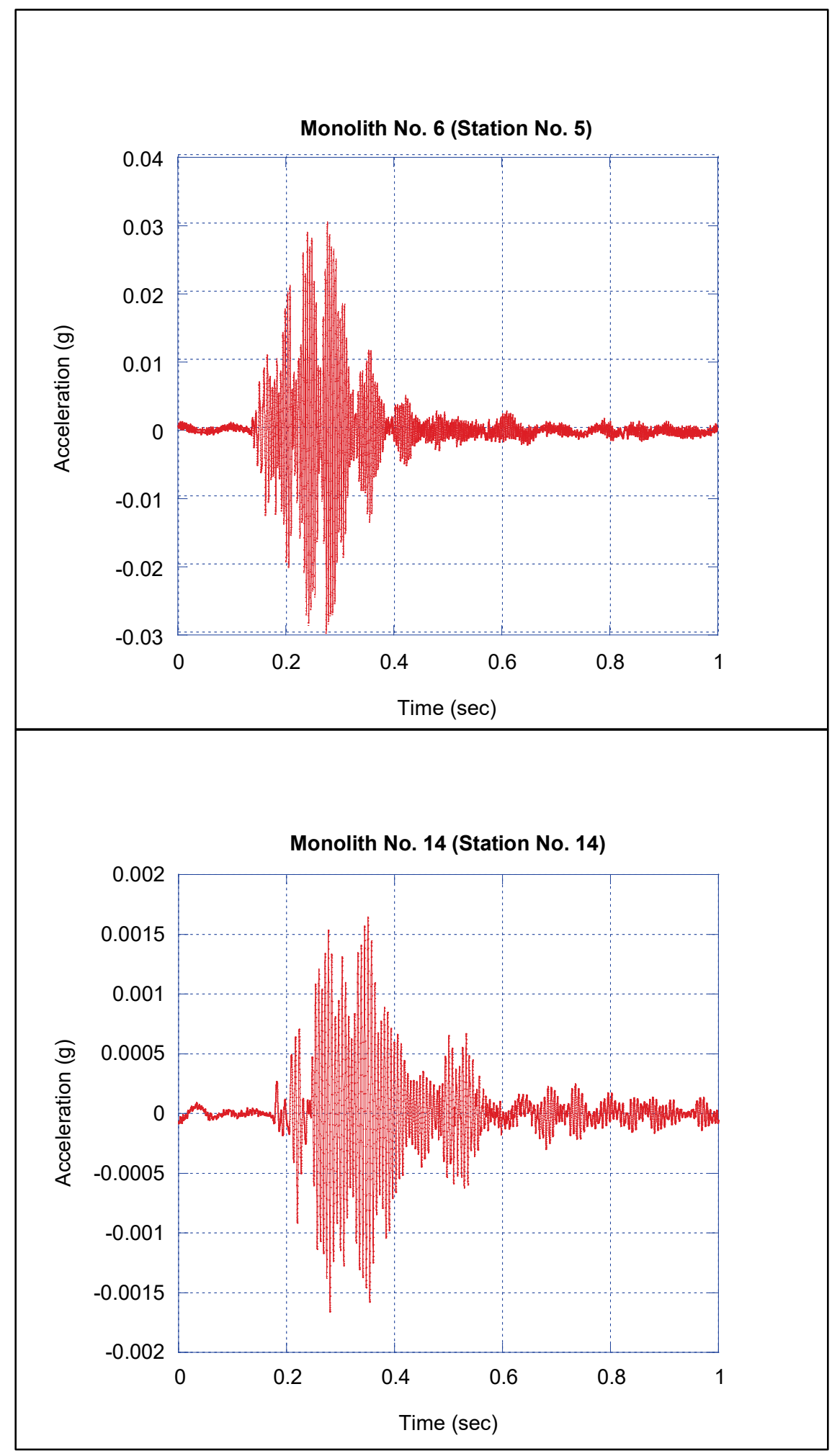


The transient characteristics indicated in these responses are consistent with previous PBTs of dams and illustrate the broad frequency content induced by the CGT. The overall nature of these responses is also consistent with that expected during seismic loading, which highlights a significant advantage of PBT over traditional testing techniques.

PBT is capable of delivering to the dam large-amplitude, short-duration loads, which generate responses that can be considered as impulse responses. These impulse responses, by definition, contain fundamental characteristics of the dam, such as resonant frequencies, that are indications of energy dissipation and relative response levels, which can be used for a variety of applications including model validation, development of performance indicators for assessing and evaluating structural condition, and prediction of response levels to hazardous loadings without the use of a numerical model. All of these applications have been conducted and reported in Duron et al. (2013).

Although the quality of the transient responses captured during PBT at Portugues Dam is considered very high, transients do not normally lend themselves to traditional analysis techniques, such as Fourier techniques. Fortunately, aerospace engineering applications to rocket flight analysis, as well as blast response behavior analysis of structures, have developed tools that can be adapted for evaluating PBT responses on large civil structures. One analysis technique that has been useful in extracting relevant behavior characteristics from the PBT responses is the Shock Response Spectrum (SRS) technique described in Duron et al. (2013).

The SRS analysis technique was used to confirm resonances in the dam and to develop an estimate of the response shape associated with the fundamental resonance. Sample SRS responses for monoliths 6 and 14 are shown in Figure 7. 
Figure 7. Sample shock response spectra associated with PBT responses at monoliths 6 and 14.
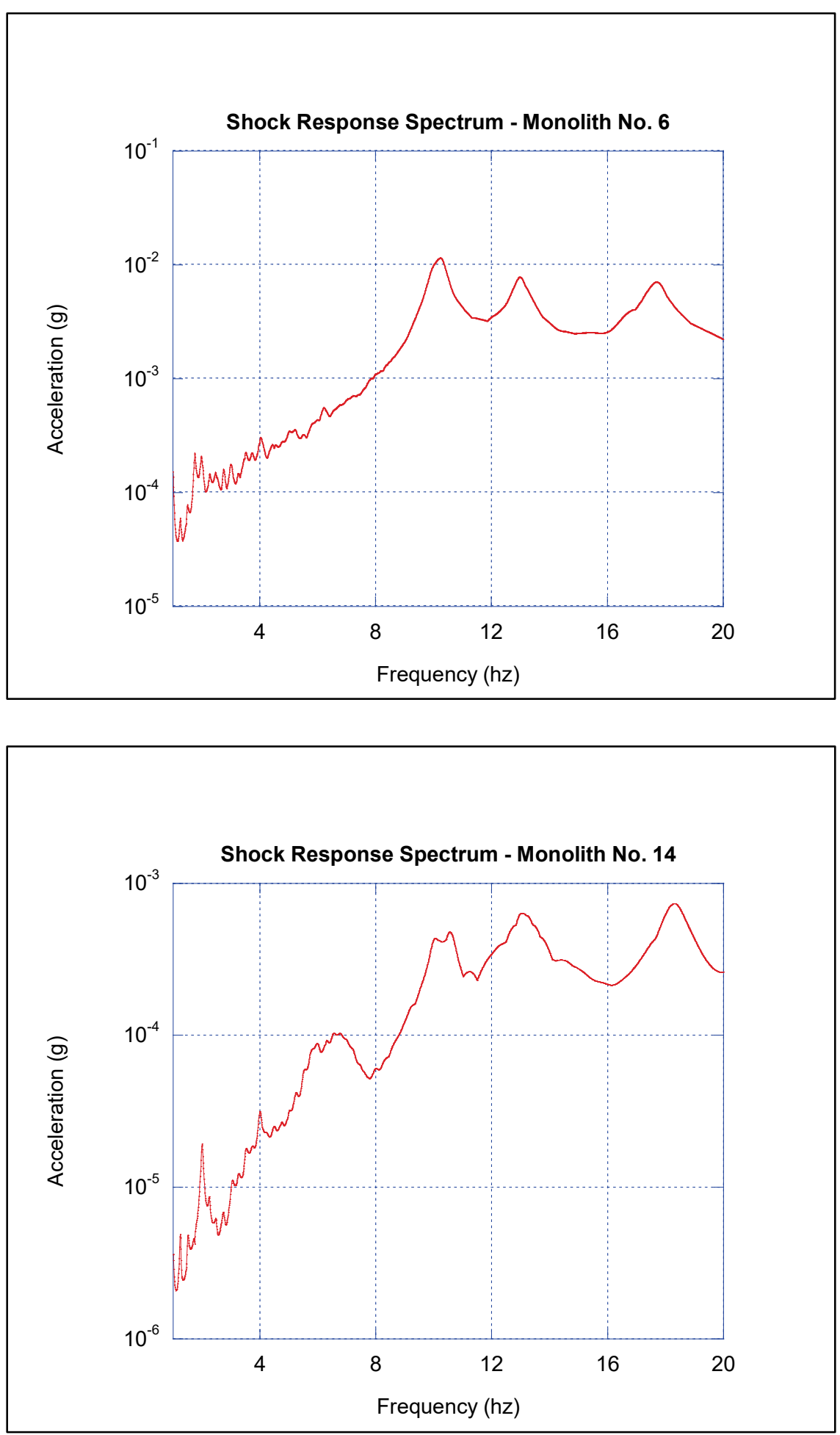
Resonances identified from PBT responses are listed in Table 1.

Table 1. Resonances identified from PBT at Portugues Dam.

\begin{tabular}{|c|c|}
\hline Resonance No. & Frequency $(\mathrm{Hz})$ \\
\hline 1 & 4.8 \\
\hline 2 & 6.6 \\
\hline 3 & 10.2 \\
\hline 4 & 13 \\
\hline 5 & 17.8 \\
\hline 6 & 20.4 \\
\hline
\end{tabular}

These values were confirmed after a review of both power spectral density (PSD) and SRS estimates for each measurement.

A simplified analysis procedure was developed based on SRS responses to obtain an estimate for the response shape associated with the fundamental resonance at $4.8 \mathrm{~Hz}$. The approach takes advantage of the fact that the unique aspect of any response shape lies in the relative amplitudes across the structure and not in the absolute magnitudes of the response. As a result, ratios of SRS response levels can be used to arrive at a response shape defined by relative magnitudes based on a reference location in the dam. Using the SRS response at monolith No. 8 as the reference, an estimate for the response shape at $4.8 \mathrm{~Hz}$ was determined, as shown in Figure 8.

Figure 8. Response shape at $4.8 \mathrm{~Hz}$; modal amplitude is normalized to 1 as indicated.

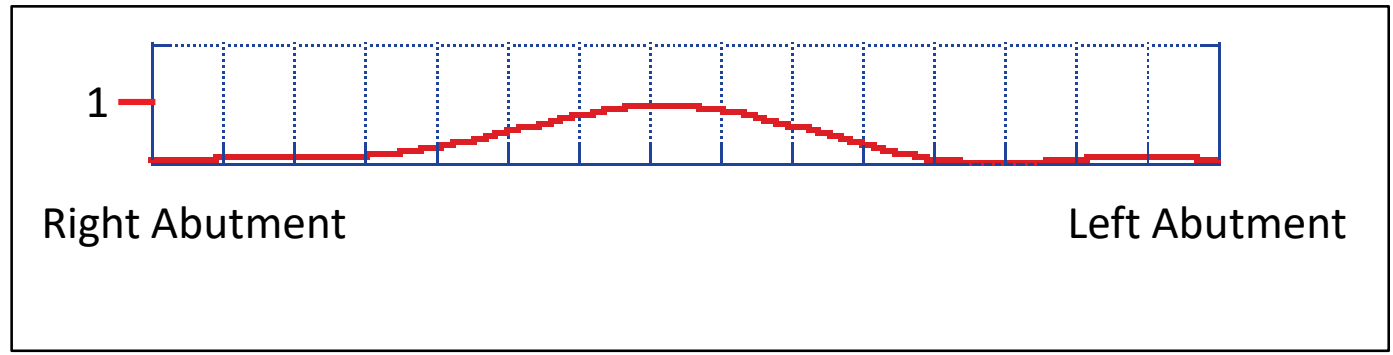

Since the ogee spillway was still under construction during PBT at Portugues Dam, no responses were acquired between monoliths 10 and 13 . Nonetheless, the response shape is consistent with expected behavior and illustrates the ability of PBT to extract eigen properties of the dam in a manner consistent with traditional techniques, including the Fourier analysis of forced vibrations in a dam. 


\section{Wave-Speed-Based Performance Indicators}

\subsection{Wave-Speed}

Wave propagation is the basis for a range of non-destructive evaluation (NDE) techniques that are aimed at uncovering weak or deteriorating concrete in structures. Olson and Sack (2007) describes the application of stress-wave-based methods for evaluating the in-place condition of concrete by using impact echo and spectral analysis of surface waves techniques. In each case, the ability to induce wave propagation and to measure velocities of propagation through the concrete are critical to the overall effectiveness of these or any wave-based NDE technique.

Estimates of wave speed can be used to define a PI that provides baseline and subsequent measures of concrete condition. PBT at Portugues Dam offers a unique opportunity to develop early in its service life indicators for the dam that can be available for future evaluations and condition assessments. Particularly in the aftermath of a significant seismic event, the ability of PBT to produce PIs for assessing and evaluating relative changes in the dam can be an important contribution to decisions regarding continued and safe operations after a hazard event.

To illustrate the ability of PBT to excite wave propagation in the dam, a timing comparison within monolith No. 8 is shown in Figure 9.

Figure 9. Wave propagation in monolith No. 8.

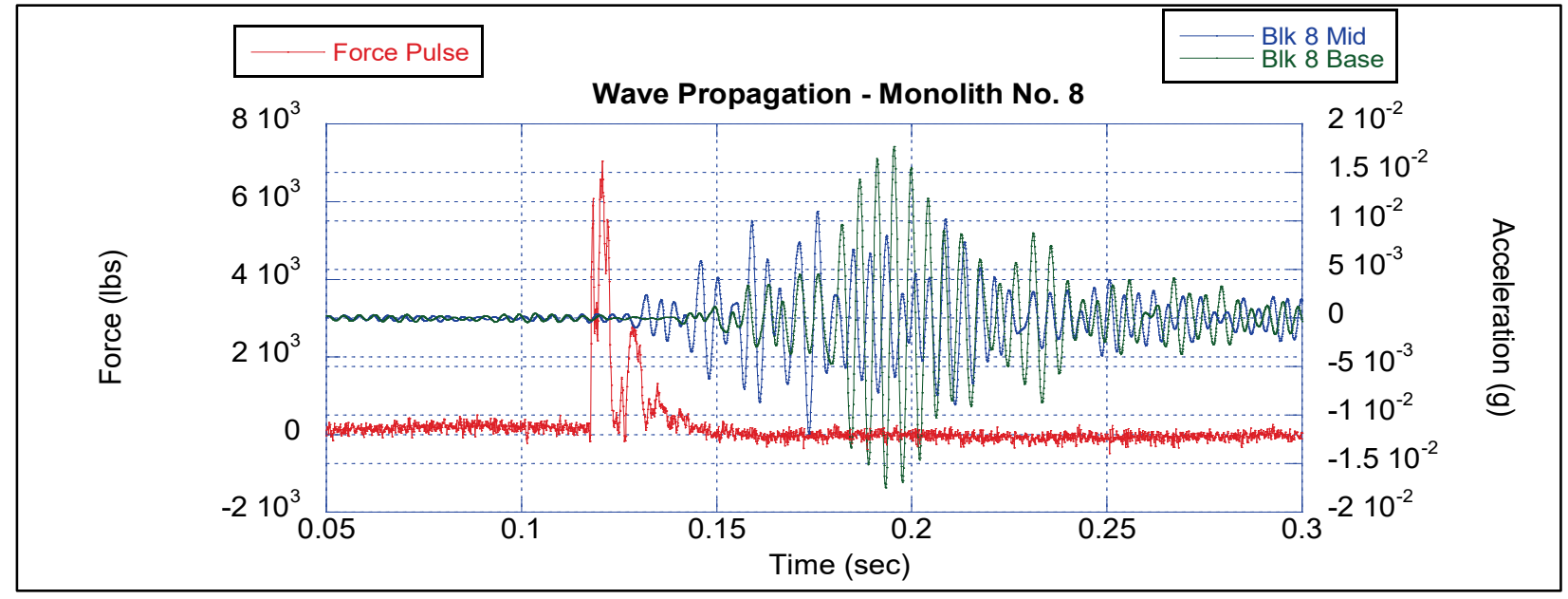


The key to developing wave speed estimates in the dam is identifying accurate and reliable wave arrival times at each measurement location either along the crest or along a single monolith. At Portugues Dam, wave speed estimates were obtained along the crest and in monolith No. 8 by using the measurement layouts shown in Figure 10.

Figure 10. Measurement layouts for determining wave speed estimates along the crest (top) and in monolith No. 8 (bottom) at Portugues Dam; locations $8 \mathrm{~b}$ and $8 \mathrm{c}$ correspond to the mid-height and the base of the monolith, respectively.
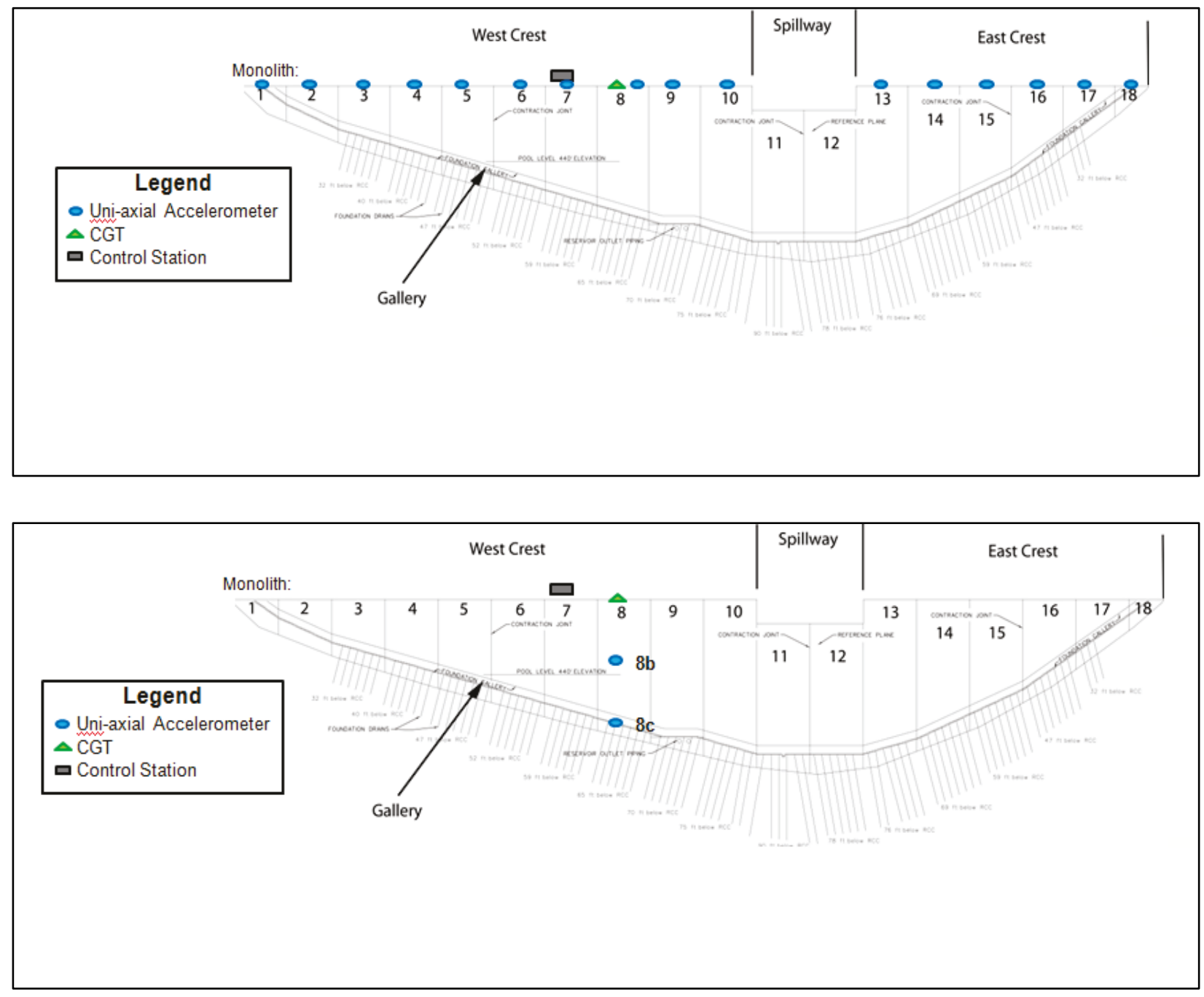

Estimates of wave speed along the west crest and in monolith No. 8 are included in Table 2. 
Table 2. Wave speed estimates along the west portion of the crest (top table) and within monolith No. 8 (bottom table). The estimates within monolith No. 8 were obtained from a series of tests that captured responses at the midpoint and the base of the monolith.

\begin{tabular}{|c|c|}
\hline Propagation Distance (ft) & Wave Speed Estimate (ft/sec) \\
\hline 52 & 5870 \\
\hline 84 & 5899 \\
\hline 122 & 5951 \\
\hline 182 & 6431 \\
\hline 256 & 5531 \\
\hline 323 & 5127 \\
\hline 390 & 5394 \\
\hline
\end{tabular}

\begin{tabular}{|c|c|}
\hline Propagation Path (ft) & Wave Speed Estimate (ft/sec) \\
\hline Crest to midpoint (92) & 6943 \\
\hline Crest to base (168) & 6720 \\
\hline Midpoint to base (76) & 6468 \\
\hline Crest to base (168) & 6788 \\
\hline Crest to midpoint (92) & 6917 \\
\hline Crest to base (168) & 6640 \\
\hline Midpoint to base (76) & 6333 \\
\hline Crest to midpoint (92) & 6970 \\
\hline Crest to base (168) & 6720 \\
\hline Midpoint to bas (76) & 6440 \\
\hline
\end{tabular}

Wave speed mean and standard deviation values along the crest and within monolith No. 8 are listed in Table 3 .

Table 3. Wave speed comparison along crest and within monolith No. 8.

\begin{tabular}{|c|c|c|}
\hline Location & Mean & Standard Deviation \\
\hline Crest & $5828 \mathrm{ft} / \mathrm{sec}$ & $429 \mathrm{ft} / \mathrm{sec}$ \\
\hline Monolith No. 8 & $6994 \mathrm{ft} / \mathrm{sec}$ & $223 \mathrm{ft} / \mathrm{sec}$ \\
\hline
\end{tabular}

The relatively small statistical variability in these results suggests that a measurable difference exists between the wave speeds along the crest and those within monolith No. 8. Two contributing factors include the presence of contraction joints that the propagating wave must cross as it travels from the point of origin (CGT located on monolith No. 8) along the crest and the absence of these joints in the path traveled by the wave 
within monolith No. 8. It is also unclear what effect, if any, is contributed by the reinforced concrete decking (which is actually the crest) over the RCC dam. Differences in wave propagation paths notwithstanding, wave speeds appear to range between 5,828-6,694 ft/sec (1.8-2.04 km/sec).

Hussein and Morgano (1993) describes results from a series of concrete pile tests in which compression waves were introduced with corresponding wave speeds ranging between 9,843-1,4764 ft/ $\mathrm{sec}(3-4.5 \mathrm{~km} / \mathrm{sec})$. The tests at Portugues Dam did not introduce compression waves in the concrete due to the orientation of the CGT that delivered its load in shear (thereby producing shear waves) however, the ratio between compression and shear wave speeds for healthy concrete can be used to define a PI for the concrete in the dam.

A wave-speed-based PI can be defined as

$$
\frac{\text { Compression Wave Speed }\left(\propto \sqrt{E}, \text { Young }^{\prime} \text { S Mod }\right)}{\text { Shear Wave Speed }(\propto \sqrt{G} \text {, Shear Mod })}=\sqrt{2(1+v)}
$$

which for healthy concrete and a nominal Poisson's ratio of 0.2 approaches a value of 1.6 .

Assuming the range for compression wave speeds in healthy concrete indicated in Hussein and Morgano (1993) is applicable to the concrete in Portugues Dam, an initial estimated range for the wave-speed-based PI of 1.7-2.2 is obtained.

\subsection{Performance Indicator meaning and interpretation}

Consider the case of a nominal dam constructed as a perfectly homogeneous monolithic structure. The structure contains no contraction or horizontal lift joints and is immune to crack formation. For this nominal dam, estimates of wave speeds through the concrete can be expected to remain constant throughout its service life with a corresponding PI at or very near to a value of 1.6 (assuming nominal concrete material properties). In this case, the PI value is completely dependent on the material properties of the concrete, since no joints or imperfections are present. Even though in reality the PI is influenced by the combined effects of the concrete's material properties and the condition of the joints in the dam, the nominal case can act as a baseline measurement. 
The range of the PI reported for Portugues Dam may be interpreted as follows.

The lower bound of 1.7 is associated with wave propagation across the contraction joints along the crest and, when compared to 1.6, suggests that the combined effects of the material properties and contraction joints mimic those of the nominal dam. In other words, the material properties and joint conditions along the crest are nominal in the sense that the concrete's material properties are likely close to those of nominal concrete, and the contraction joints are sufficiently close to facilitate nominal wave propagation along the crest. On the other hand, the upper bound of 2.2 that corresponds to wave propagation across the horizontal lift joints in a single monolith of Portugues Dam exceeds the baseline by $37.5 \%$, which may be interpreted as follows.

The higher valued PI (2.2 versus the nominal value of 1.6) suggests that, while the compression wave speeds may be at or close to nominal, the shear wave speeds may be less, thus contributing to the larger value. If this interpretation is correct, it may suggest that the horizontal lift joints in the RCC dam contribute to slower propagation speeds in shear. Since the PI depends on the combined effects of the joint and concrete conditions, it cannot be used to separate the effects of presumed changes in joint or concrete conditions on the indicator values. Nonetheless, the lower and upper values of the PI can serve as baseline values for Portugues Dam.

From the perspective of a PI, subsequent or periodic testing that produces variations from known baseline values can contribute to informed inspection and maintenance strategies for the dam. Furthermore, and where appropriate, the indicator may also be used to evaluate numerical model representations of the dam. 


\section{Summary and Observations}

The PBTs conducted on Portugues Dam represent the first of its kind to be conducted on a large RCC dam. A CGT mounted to the crest of the dam delivered impulse loads that induced large-amplitude, broad-frequencyband transient behavior throughout the structure. The type and quality of the measured PBT responses were consistent with previous experiences on other large concrete dams. Subsequent analyses of the measured behavior produced estimates of resonant frequencies and response shapes and facilitated a wave-speed-based PI for assessing and evaluating the condition of the concrete in the dam.

A nominal, homogeneous, monolithic dam provides a basis for evaluating conditions in an actual dam based on wave propagation characteristics observed during PBT. For the nominal dam, the ratio of compression wave to shear wave speeds in concrete is at or very near 1.6 for nominal material properties. This ratio defines a PI that can be measured for any dam and subsequently monitored through periodic PBT. At Portugues Dam, the corresponding wave-speed PI ranged from 1.7 (for propagation across contraction joints) to 2.2 (for propagation across horizontal lift joints). This range can be used as a baseline to evaluate suspected changes in condition after significant hazardous loading events over the life of the dam.

Additional testing on concrete dams is recommended to gain more insight into this PI and its sensitivity to changes in concrete and joint conditions. 


\section{References}

Duron, Z. H., J. Edelman, M. Goldkamp, P. Orme, and T. Savage. 2013. Performance based testing of large concrete dams. Journal of Dams Safety 11(3):9-12.

Edelman, B. J., P. J. Orme, R. M. Goldkamp, T. Savage, and Z. H. Duron. 2014. Performance based analysis of a large concrete dam. USSD Annual Meeting and Conference Dams and Extreme Events. San Francisco, CA.

Goldkamp, R. M., T. Savage, B. J. Edelman, P. J. Orme, and Z. H. Duron. 2014. Performance based testing of a large concrete dam. 34th USSD Annual Meeting and Conference Dams and Extreme Events. San Francisco, CA.

Hussein, M., and M. Morgano. 1993. Structural integrity evaluation of concrete piles from stress wave measurements. The Society for Experimental Mechanics Conference on Nondestructive Testing of Concrete in the Infrastructure. Dearborn, MI.

Olson, L. D., and D. A. Sack. 2007. Nondestructive evaluation of concrete dams and other structures. In Proceedings of the SPIE, Volume 2457:113-124. Bellingham, WA: International Society for Optics and Photonics. 


\section{REPORT DOCUMENTATION PAGE}

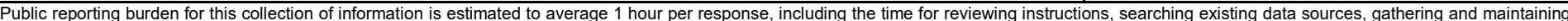

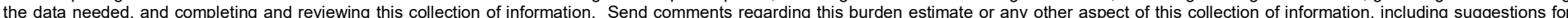

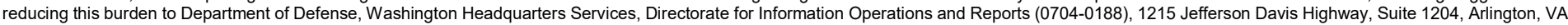

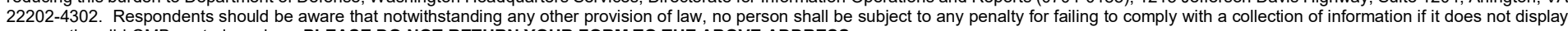
a currently valid OMB control number. PLEASE DO NOT RETURN YOUR FORM TO THE ABOVE ADDRESS.
1. REPORT DATE (DD-MM-YYYY) 2. REPORT TYPE
3. DATES COVERED (From - To)

October 2018 Final

\section{TITLE AND SUBTITLE}

Wave-Speed-Based Performance Indicators for Portugues Dam 5a. CONTRACT NUMBER

5b. GRANT NUMBER

5c. PROGRAM ELEMENT NUMBER

\section{AUTHOR(S)}

5d. PROJECT NUMBER

Ziyad H. Duron, Peter Orme, Spenser Anderson, Henry Diaz-Alvarez, Vincent P. Chiarito, and Mihan H. McKenna

5e. TASK NUMBER

5f. WORK UNIT NUMBER

33143

\section{PERFORMING ORGANIZATION NAME(S) AND ADDRESS(ES)}

8. PERFORMING ORGANIZATION REPORT NUMBER

Geotechnical and Structures Laboratory

U.S. Army Engineer Research and Development Center

ERDC/GSL TR-18-28

3909 Halls Ferry Road

Vicksburg, MS 39180-6199

\section{SPONSORING / MONITORING AGENCY NAME(S) AND ADDRESS(ES)}

U.S. Army Corps of Engineers

Washington, DC 20314-1000

10. SPONSOR/MONITOR'S ACRONYM(S)

USACE

11. SPONSOR/MONITOR'S REPORT NUMBER(S)

\section{DISTRIBUTION / AVAILABILITY STATEMENT}

Approved for public release; distribution is unlimited.

\section{SUPPLEMENTARY NOTES}

\section{ABSTRACT}

Roller Compacted Concrete (RCC) construction techniques are used to raise existing dams and to build new dams. A particular and assumed advantage of the RCC technique is improved homogeneity in concrete condition throughout the dam. An opportunity to evaluate this on a large RCC dam was made available by the U.S. Army Corps of Engineers at Portugues Dam. Through the application of a relatively new testing technique, estimates of a wave-speed-based Performance Indicator (PI) of the dam were obtained. The PI relates wave speeds associated with shear wave propagation in the dam to compression wave speeds for healthy concrete. Values ranging from 1.7-2.2 for Portugues Dam compare favorably to a value of 1.6 for nominal concrete. .

\begin{tabular}{|ll}
\hline 15. SUBJECT TERMS & Natural frequencies \\
Infrasounds & Dam vibrations \\
Model analysis & CGT \\
Dams - Puerto Rico - design and & Concrete dams
\end{tabular}

construction
Roller compacted concrete - Testing

\section{SECURITY CLASSIFICATION OF:}

\begin{tabular}{|l|l|}
\hline a. REPORT & b. ABSTRACT \\
Unclassified & Unclassified \\
\hline
\end{tabular}

17. LIMITATION OF ABSTRACT

:

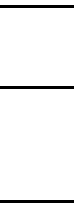

\begin{tabular}{|c|}
\hline \multicolumn{2}{|c|}{ c. THIS PAGE } \\
Unclassified
\end{tabular}

OF ABSTRACT

\section{PBT}

Portugues Dam

RCC

Wave propagation

\begin{tabular}{|c|l|}
$\begin{array}{l}\text { 18. NUMBER } \\
\text { OF PAGES }\end{array}$ & $\begin{array}{l}\text { 19a. NAME OF RESPONSIBLE } \\
\text { PERSON }\end{array}$ \\
\cline { 2 - 2 } 25 & $\begin{array}{l}\text { 19b. TELEPHONE NUMBER (include } \\
\text { area code) }\end{array}$ \\
\hline
\end{tabular}

